\title{
Perception of consonant clusters in Japanese native speakers: influence of foreign language learning
}

Hinako Masuda and Takayuki Arai

Department of Science and Technology, Sophia University, Japan

https://doi.org/10.36505/ExLing-2008/02/0041/000100

\begin{abstract}
Previous research on the perception of consonant clusters by Japanese native speakers has revealed that they are highly likely to perceive a vowel between the two consonants even if there are no vowels inserted (Dupoux et al. 1999). The present study further investigates this issue but by dividing the group of Japanese native speakers into two groups: Japanese-English bilinguals and Japanese monolinguals. This study aims to look into the influence of language learning experience on the perception of foreign sounds. Results of the perception test revealed that bilinguals made less error than monolinguals in identifying pseudowords with and without consonant cluster.
\end{abstract}

Key words: consonant cluster, epenthetic vowel, bilingual, speech perception

\section{Introduction}

Numerous previous studies have shown that one's native language has a great effect on the perception of foreign sounds (Miyawaki et al., 1975; Peperkamp et al., 1999; Takagi, 2002; Sebastian-Galles, 2005). Previous study by Dupoux et al. (1999) has revealed that Japanese native speakers are more likely to perceive an 'illusory vowel' between two consonants even if no vowels are inserted. This is due to the difference in the phonotactic structure of French and Japanese. While French allow consonant clusters, Japanese does not; therefore, Japanese apply the rules of the Japanese phonotactics when hearing foreign sounds.

Consonant clusters are also common in English. Below are some English words introduced to the Japanese language. Japanese often insert the vowel $[\mathrm{u}]$ between consonants to avoid consonant clusters (Nishimitsu, 2004).

$$
\begin{array}{ll}
\text { kiss }[\mathrm{kis}]: / \mathrm{kis} u / & \text { milk [milk] :/mir } u \mathrm{k} u / \\
\text { cat }[\mathrm{kæt}]: / \mathrm{kjat} . \mathrm{to} / & \text { ice cream [aiskri:m] :/ais } u \mathrm{k} u \text { riim } u /
\end{array}
$$

In the present study, we aim to investigate the perception of pseudowords with and without consonant clusters by dividing the Japanese native speaker group into two: Japanese-English bilinguals and Japanese monolinguals. By investigating the difference of perceptual ability, we will be able to see how different language learning backgrounds affect foreign language perception.

ExLing 2008: Proceedings of 2nd Tutorial and Research Workshop on Experimental Linguistics, 25-27 August 2008, Athens, Greece 


\section{Experiment}

The present experiment aims to investigate the difference in the perceptual ability between two groups of native speakers of Japanese: Japanese-English bilinguals and Japanese monolinguals.

\section{Participants}

17 Japanese-English bilinguals, 12 women and 5 men, and 22 Japanese monolinguals, 8 women and 14 men, participated in this experiment.

All bilinguals have experience of living in an English-speaking country and receiving education in an English-speaking school for at least 2 years. None of the monolinguals, on the other hand, have experience of overseas for more than one month.

The ages ranged from 19 to 25 for bilinguals (average of 23.4 years), and 18 to 25 for monolinguals (average of 20.8 years). The length of overseas experience for bilinguals ranged from 2 to 8.5 years (average of 5.7 years). None of the participants reported any hearing problems.

\section{Stimuli}

The speaker of the recorded stimuli used in the perception experiment is a Japanese-French bilingual speaker. Her first language is Japanese, and is highly fluent in both languages. She is also an experienced phonetician.

36 pseudowords (18 pairs of pseudoword sets with and without consonant clusters) were produced in the sentence "Dites (pseudoword) deux fois." [Say (pseudoword) two times.] Each word was recorded three times. 16 pairs of pseudowords were used as stimuli for the experiment, and the remaining 2 pairs (abmo/abumo, ebzo/ebuzo) were used for practice trials. The pseudowords are listed in Table 1.

Table 1. The list of 18 pairs of pseudowords (36 pseudowords) with and without consonant clusters.

\begin{tabular}{|l|l|l|l|}
\hline VCCV & VCVCV & VCCV & VCVCV \\
\hline abge & abuge & eshmo & eshumo \\
abmo & abumo & ibdo & ibudo \\
agmi & agumi & igna & iguna \\
akmo & akumo & ikma & ikuma \\
ashmi & ashumi & ishto & ishuto \\
ebza & ebuza & obni & obuni \\
ebzo & ebuzo & ogza & oguza \\
egdo & egudo & okna & okuna \\
ekshi & ekushi & oshta & oshuta \\
\hline
\end{tabular}




\section{Procedure}

The participants were instructed to listen to the 3 words through headphones, and to judge whether the second word was more similar to the first or the third word. The order of the presented words (VCCV-VCVCV order or VCVCV-VCCV order) was randomized. This identification experiment consisted of 192 trials (32 words x 2 orders x 3 sets of recorded words) after 8 practice trials. The participants received no feedback on the practice trials.

\section{Results}

The Mann-Whitney test found a significant difference between the two groups of participants $(p<0.05)$. Table 2 shows the average, range, and percentages of the number of errors made by each participant group.

Table 2. The average and range of the number of errors (\% of errors) made by bilinguals and monolinguals. The Mann-Whitney test found a significant difference between the two groups $(p<0.05)$.

\begin{tabular}{|l|l|l|}
\hline & Bilingual $(\mathrm{n}=17)$ & Monolingual $(\mathrm{n}=22)$ \\
\hline Average & $3.8(1.9 \%)$ & $13.1(6.8 \%)$ \\
\hline Range & $0-12(0-6.2 \%)$ & $2-35(1-18.2 \%)$ \\
\hline
\end{tabular}

\section{Discussion}

The perception experiment conducted in the present research aimed to find the difference in the identification ability between Japanese-English bilinguals and Japanese monolinguals. The stimuli used were pseudowords with and without consonant clusters. The results of the experiment showed that there was a significant difference in the number of errors made by the two participant groups.

The result of the experiment revealed that there is a difference in the perceptual ability of consonant clusters depending on whether the participants have experience of living abroad. However, the percentages of correct answers were above $90 \%$ for both groups. This may have been caused by the stimuli used. The present research used stimuli that were neither digitally processed nor spoken fast in speed. The difference between the two groups' results may be larger if the stimuli had been produced in a more natural, faster speed instead of slow speed which may unconsciously cause vowel epenthesis. Further research will be performed with improved stimuli. 


\section{Acknowledgents}

This study work was partially supported by Sophia University Open Research Center from MEXT.

\section{References}

Dupoux, E., Kakehi, K., Hirose, Y., and Pallier, C. 1999. Epenthetic Vowels in Japanese: a Perceptual Illusion? Journal of Experimental Psychology: Human Perception and Performance, Volume 25, Number 6, 1568-1578.

Miyawaki, K., Strange, W., Verbrugge, R., Liberman, A., Jenkins, J., and Fujimura, O. 1975. An effect of linguistic experience: The discrimination of $/ \mathrm{r} /$ and $/ 1 /$ by native speakers of Japanese and English. Perception and Psychophysics 18, 331340.

Nishimitsu, Y. (ed) 2004. Nishieigo taisho ni yoru eigogakugairon zouhoban. Tokyo, Kuroshio Publishers.

Peperkamp, S., Dupoux, E., and Sebastian-Galles, N. 1999. Perception of stress by French, Spanish, and bilingual speakers. Eurospeech '99 Proceedings, ESCA 7th European Conference on Speech Communication and Technology, vol.6, 26832686.

Sebastian-Galles, N. 2005. Cross-Language Speech Perception. The Handbook of Speech Perception, 546-566, Australia, Blackwell Publishing.

Takagi, N. 2002. The limits of training Japanese listeners to identify English $/ \mathrm{r} / \mathrm{and}$ /1/: Eight case studies. Journal of the Acoustical Society of America 111(6), 28872896. 